\title{
Vadillo Floran et Papaemmanuel Alexandre, Les espions de l'Élysée, Le Président et les services de renseignement
}

Paris, Tallandier, 2019, 328 p.

Philippe Boulanger

\section{OpenEdition}

\section{Journals}

Édition électronique

URL : https://journals.openedition.org/geohist/1451

DOI : 10.4000/geohist.1451

ISSN : 2264-2617

Éditeur

Association française de la Revue de géographie historique

\section{Référence électronique}

Philippe Boulanger, « Vadillo Floran et Papaemmanuel Alexandre, Les espions de l'Élysée, Le Président et les services de renseignement », Revue de géographie historique [En ligne], Comptes-rendus, mis en ligne le 08 juin 2021, consulté le 12 juin 2021. URL : http://journals.openedition.org/geohist/1451 ; DOI : https://doi.org/10.4000/geohist.1451

Ce document a été généré automatiquement le 12 juin 2021.

\section{(c) (i) (9)}

Ce(tte) œuvre est mise à disposition selon les termes de la Licence Creative Commons Attribution Pas d'Utilisation Commerciale - Pas de Modification 4.0 International. 


\section{Vadillo Floran et Papaemmanuel Alexandre, Les espions de l'Élysée, Le Président et les services de renseignement}

Paris, Tallandier, 2019, 328 p.

Philippe Boulanger

\section{RÉFÉRENCE}

Vadillo Floran et Papaemmanuel Alexandre, Les espions de l'Élysée, Le Président et les services de renseignement,

Paris, Tallandier, 2019, 328 p.

1 Le domaine de l'espionnage et du renseignement continue de susciter une certaine curiosité du grand public sinon un certain mystère entretenu par la règle du secret. L'ouvrage de Floran Vadillo (Science Po Paris) et Alexandre Papaemmanuel (Ihedn), tous deux experts de ce domaine, nous apporte quantités d'informations actuelles sur le sujet bien qu'il ne soit pas géographique à proprement parler. Le regard du géographe se trouve dans l'appréhension des lieux de pouvoirs et de crises que les auteurs mentionnent (Syrie, Ukraine, etc.). Il se veut encore plus géopolitique lorsque la question porte sur les relations entre le Président de la République et les directeurs des agences dédiées à cette activité.

2 Car l'ouvrage ne constitue pas une synthèse de plus sur le sujet. Il est un recueil d'entretiens -parfaitement mis en forme dans un style fluide- auprès des grands acteurs du renseignement français (Bernard Barjolet, Claude Guéant, Christophe Gomart, Alain Zabulon entre autres) et étranger depuis la fin des années 2000. Il attire notamment notre attention sur le Conseil national du renseignement qui coordonne les cinq agences en France et dont la création est fixée en 2008. Qui sont les acteurs qui 
renseignent le Président sur les zones de crise? Comment les agences de renseignement françaises se sont adaptées à une géopolitique mondiale toujours complexe? Quel rouage administratif est mis en place pour donner le tempo à ces organismes qui bénéficient d'une politique de développement depuis 2008 ? Les deux auteurs nous livrent à la fois des analyses bien menées et des entretiens inédits. Il est à noter un chapitre entier consacré à François Hollande (2012-2017) qui nous apporte l'avis de l'ancien Président sur ces grandes questions.

3 L'ouvrage s'articule en trois parties (Naissance d'une institution, l'inconstance de Nicolas Sarkozy (2008-2011) ; Le temps des mutations (2011-2015); La recherche d'un supplément d'âme (2015-2017), suivies d'un appendice sur le Director of National Intelligence aux EtatsUnis en comparaison avec la situation française. Il se veut accessible pour le grand public et permet de mieux saisir la manière dont certaines crises sont appréhendées par les décideurs: les attentats sur le territoire national, les organisations criminelles internationales au Moyen-Orient et en Afrique, la crise ukrainienne depuis 2013, l'affaire Snowden en 2013 et bien d'autres. 